\title{
Generation of transgene-free PDS mutants in potato by Agrobacterium-mediated transformation
}

\author{
Zsófia Bánfalvi* [D, Edina Csákvári, Vanda Villányi and Mihály Kondrák
}

\begin{abstract}
Background: Gene editing using the CRISPR/Cas9 system has become a routinely applied method in several plant species. The most convenient gene delivery system is Agrobacterium-mediated gene transfer with antibiotic selection and stable genomic integration of transgenes, including Cas9. For elimination of transgenes in the segregating progeny, selfing is applied in many plant species. This approach, however, cannot be widely employed in potato because most of the commercial potato cultivars are self-incompatible.
\end{abstract}

Results: In this study, the efficiency of a transient Cas9 expression system with positive/negative selection based on codA-nptll fusion was tested. The PHYTOENE DESATURASE (PDS) gene involved in carotenoid biosynthesis was targeted. A new vector designated PROGED::gPDS carrying only the right border of T-DNA was constructed. Using only the positive selection function of PROGED::gPDS and the restriction enzyme site loss method in PCR of genomic DNA after digestion with the appropriate restriction enzyme, it was demonstrated that the new vector is as efficient in gene editing as a traditional binary vector with right- and left-border sequences. Nevertheless, 2 weeks of positive selection followed by negative selection did not result in the isolation of PDS mutants. In contrast, we found that with 3-day positive selection, PDS mutants appear in the regenerating population with a minimum frequency of 2-10\%. Interestingly, while large deletions (> $100 \mathrm{bp}$ ) were generated by continuous positive selection, the 3-day selection resulted in deletions and substitutions of only a few bp. Two albinos and three chimaeras with white and green leaf areas were found among the PDS mutants, while all the other PDS mutant plants were green. Based on DNA sequence analysis some of the green plants were also chimaeras. Upon vegetative propagation from stem segments in vitro, the phenotype of the plants obtained even by positive selection did not change, suggesting that the expression of Cas9 and gPDS is silenced or that the DNA repair system is highly active during the vegetative growth phase in potato.

Conclusions: Gene-edited plants can be obtained from potatoes by Agrobacterium-mediated transformation with 3-day antibiotic selection with a frequency high enough to identify the mutants in the regenerating plant population using PCR.

Keywords: Agrobacterium, Chimaera, CRISPR/Cas9, Gene editing, Potato, Transgene-free, Transformation

\footnotetext{
* Correspondence: banfalvi.zsofia@abc.naik.hu

Mihály Kondrák is deceased.

NARIC Agricultural Biotechnology Institute, H-2100 Szent-Györgyi A. u. 4.,

Gödöllő, Hungary
}

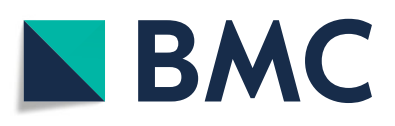

(c) The Author(s). 2020 Open Access This article is licensed under a Creative Commons Attribution 4.0 International License, which permits use, sharing, adaptation, distribution and reproduction in any medium or format, as long as you give appropriate credit to the original author(s) and the source, provide a link to the Creative Commons licence, and indicate if changes were made. The images or other third party material in this article are included in the article's Creative Commons licence, unless indicated otherwise in a credit line to the material. If material is not included in the article's Creative Commons licence and your intended use is not permitted by statutory regulation or exceeds the permitted use, you will need to obtain permission directly from the copyright holder. To view a copy of this licence, visit http://creativecommons.org/licenses/by/4.0/. The Creative Commons Public Domain Dedication waiver (http://creativecommons.org/publicdomain/zero/1.0/) applies to the data made available in this article, unless otherwise stated in a credit line to the data. 


\section{Background}

Genome editing strategies based on the Clustered Regulatory Interspaced Short Palindromic Repeat (CRISPR)-Associated Protein System (CRISPR/Cas9) were first shown to be effective in bacteria and mammalian cell lines, but they have been rapidly adapted for plant genome modification [1]. The CRISPR/Cas9 system has been used successfully in several food crops, including the most important Solanaceae species, tomato and potato $[2,3]$.

The first reports on successful CRISPR/Cas9-based genome editing in potato (Solanum tuberosum L.) were published in 2015. Wang et al. [4] cloned the native U6 RNA promoter from potato to drive an oligo encoding singleguide RNA (sgRNA), which then acts as a guide to the specific site of the genome where Cas9 is able to cleave double-stranded DNA, leading to deletion, insertion or substitution at the target site. The Cas 9 used was derived from Streptococcus pyogenes and codon-optimised for rice [5]. It was driven by the CaMV $35 S$ promoter and cloned with the U6 promoter::sgRNA into the binary vector pCAMBIA2300 and designated CP025. To test whether this CRISPR/Cas9 construct can introduce gene knockouts via Agrobacterium-mediated transformation, the $I A A 2$ encoding an auxin/indole-3-acetic acid family member protein was targeted in the double-haploid DM potato. Mono- and biallelic homozygous mutants, as well as heterozygous plants, were obtained without off-target mutations, demonstrating that the CRISPR/Cas9 system can be used for targeted mutagenesis in potato.

Butler et al. [6] targeted the ACETOLACTATE SYNT HASE1 (ALS1) gene in a diploid breeding line and the tetraploid potato cultivar 'Désirée' using Agrobacteriummediated transformation with either a conventional $\mathrm{T}$ DNA or a modified geminivirus T-DNA. Both constructs were capable of generating targeted mutations leading to a reduced herbicide susceptibility phenotype. Single targeted mutations in primary events were capable of being carried through clonal generations and inherited through the germline as Cas9-free progeny. Later, it was demonstrated that with geminivirus replicons, even point mutations can be generated in potatoes [7].

The majority of potato cultivars possess gametophytic self-incompatibility. Thus, in most cases, selfing is not an applicable method to eliminate foreign genes and DNA fragments from the potato genome. Out-crossing also cannot be a good strategy, since potato is highly heterozygous. Thus, important traits would be lost in the next generation, which could be retained only by several back-crosses [8]. To avoid this problem, transient transfection and regeneration of protoplasts was used, or CRISPR-Cas9 ribonucleoproteins (RNPs) were delivered into protoplasts to alter the quality of starch by full knockout of the GRANULE-BOUND STARCH SYNT HASE (GBSS) gene $[9,10]$. In $2-3 \%$ of the regenerated shoots from the RNP experiments, mutations were induced in all four alleles, resulting in a complete knockout of the GBSS enzyme function [10]. It was shown, however, that regeneration of potato plants from protoplasts induces widespread genome instability [11]. Furthermore, the regeneration method from protoplasts is not developed for a wide range of potato cultivars.

The most convenient gene delivery system for most crops is based on Agrobacterium-mediated gene transfer [12]. Chen et al. [13] reported a method for using Agrobacterium to transiently express Cas 9 and sgRNA in plant cells, using tobacco as a model plant and $P H Y$ TOENE DESATURASE (PDS) involved in carotenoid biosynthesis as a model target gene. However, a highthroughput screening protocol utilising next-generation sequencing in combination with high-resolution DNA melting (HRM) analysis was needed to efficiently identify mutants from a population of shoots regenerated in the absence of selection pressure. Recently, transgene-free tomato and potato mutants were successfully isolated by Agrobacterium-mediated delivery of a CRISPR/Cas9 cytidine base editor [14]. In this experiment, the $A L S$ genes of potato were targeted, and after 2 weeks of kanamycin $(\mathrm{Km})$ selection pressure, plant tissues were transferred to a selective medium containing chlorsulfuron for selection of $A L S$ mutants. It was found that $10 \%$ of the mutants were transgene-free. Nevertheless, in the case of most of the target genes, there is no choice for the selection of edited plants.

In this paper, we report the results of testing the efficiency of a transient Agrobacterium-mediated genomeediting system by targeting the PDS gene in the cultivar 'Désirée' after two different intervals of $\mathrm{Km}$ selection followed either by lack of selection pressure or counterselection for regeneration of plants with integrated transgenes. We demonstrate that while no transgenefree mutants could be obtained after 2 weeks of positive selection followed by negative selection, $\mathrm{Km}$ selection for 3 days resulted in the generation of transgene-free PDS mutants with a minimum frequency of $2-10 \%$.

\section{Results}

\section{Construction and testing the efficiency of a novel vector for gene editing}

We previously reported that a binary vector, designated PROGMO, utilising an $R / R s$ recombinase system and a codA-nptII bi-functional, positive/negative selectable marker gene was successfully used for the generation of marker- and backbone-free transgenic potato plants [15]. PROGMO carries only the right border $(R B)$ of TDNA, and consequently, the whole plasmid will be inserted as one long T-DNA into the plant genome. This plasmid was converted to a vector suitable for gene editing. The recombinase gene was removed and replaced 
by the Cas9-sgRNA-scaffoldRNA-coding fragment derived from CP025 [4]. The novel vector was designated PROGED (Fig. 1).

To test the gene-editing efficiency of PROGED, PDS was selected as a target gene expecting the visible albino phenotype of PDS null mutants. The PDS gene of tomato cultivar 'Micro Tom' was edited by Pan et al. [16] using two different 20-bp PDS regions. One of them, sgRNA2 designed to exon7, carried an MlyI restriction site. This provided the possibility of easy detection of mutations at the targeted locus by the restriction enzyme site loss method using PCR of genomic DNA after digestion with MlyI. To see how conserved this locus is in the potato cultivar 'Désirée', primers suitable for amplification of an approximately 550-bp region embodying the 20-bp PDS region were designed (Additional file 1: Table S1) and the targeted region amplified from genomic DNA. The PCR product was cloned into pGEM-T Easy and 10 clones were Sanger-sequenced. The 20-bp region had identical sequences in each clone with the corresponding tomato sequence (Additional file 2: Fig. S1). Thus, the 20-bp oligo was inserted into CP025 and moved into PROGED, resulting in PROGED:::gPDS (Fig. 1).

In the first experiment, the efficiency of $\mathrm{CP} 025$ and PROGED vectors was compared using two $A$. tumefaciens strains, namely, gv2260 and LBA4404, in tuber transformation and with continuous $\mathrm{Km}$ selection for stable integration of gene-editing constructs. After regeneration and rooting, genomic DNA was isolated from the plants, and without and with digestion with MlyI, the 550-bp PDS fragment including the targeted region was PCRamplified. The PCR fragments were separated on an agarose gel. In sum, 144 putative transgenic plants were obtained, 62 of which were analysed on gels. In addition to the original size, fragments smaller than $550 \mathrm{bp}$ were detected in the majority of the samples (Fig. 2a), indicating large deletions in the targeted region. The frequency of mutation was notably high (47-88\%). No substantial difference in the efficiency of CP025- and PROGEDmediated mutagenesis was found (Table 1). Two albino plants (one of them is shown in Fig. 3a) with large deletions were obtained. One chimaeric "tabby" plant characterised by white areas, especially at leaf edges (Fig. 3b), and a large deletion in the PDS region (Fig. 2, lane 9) was also found. All other plants were green and did not differ from the non-transformed 'Désirée' in phenotype (Fig. 3c).

In the second experiment, PROGED with $g P D S$ was used for leaf transformation by the two Agrobacterium strains and with continuous $\mathrm{Km}$ selection. The efficiency of leaf mutagenesis was similar to the efficiency of tuber mutagenesis. Based on PCR fragment detection in agarose gels, 16 PDS mutants were identified out of 40 regenerated plants (Table 1). The majority of these mutants also possessed a large deletion in the targeted region (Fig. 2b).

The presence and expression of Cas 9 was tested in seven PDS mutant plants by PCR and RT-PCR, respectively. Cas 9 was present in six plants. Low amounts of Cas 9 mRNA were detected in four plants (Additional file 3: Fig. S1). Except for albino plants, which were not rooted, the tested PDS mutants, including "tabby", were maintained and propagated in vitro for more than a year. No obvious changes in phenotype were visible on the mutant lines.

\section{Testing the efficiency of PROGED-mediated gene editing} with 2-week selection

The bi-functional translationally fused marker gene codA-nptII provides a positive selection for transformation events with $\mathrm{Km}$ in the media and negative selection for the presence/genomic insertion of transgenes with 5-fluorocytosine (5-FC) in the media. The negative selection is based on the enzymatic function of CodA, which converts the non-toxic 5-FC to cytotoxic 5-

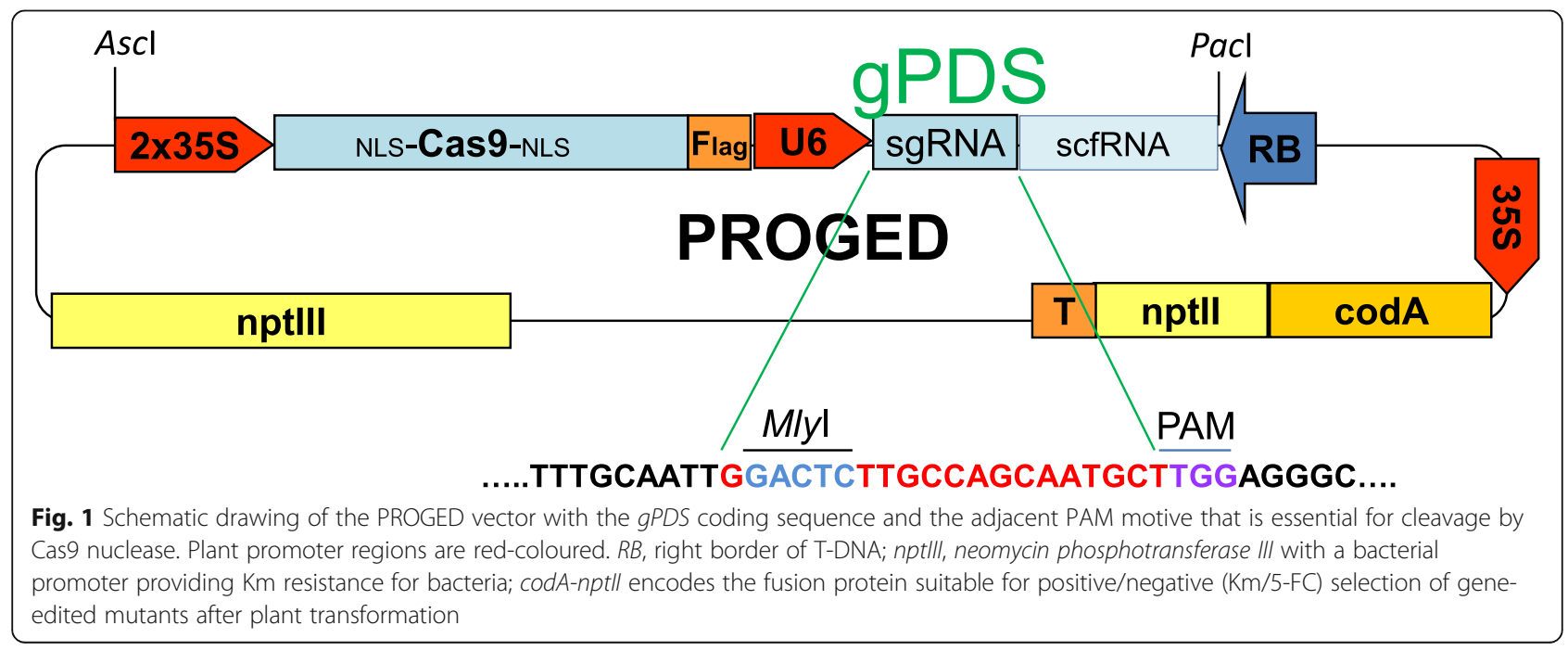



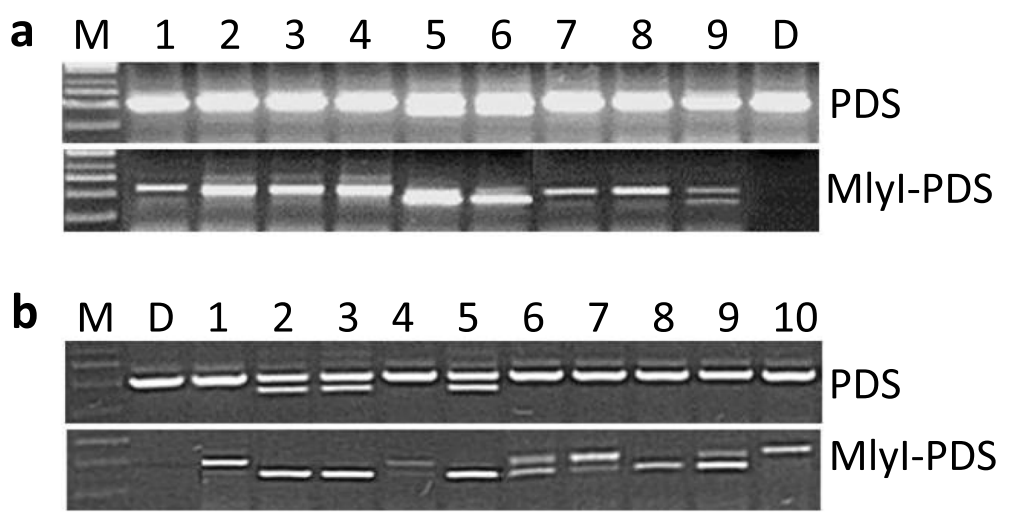

Fig. 2 Detection of target mutations obtained with continuous Km selection in the PDS gene of potatoes by PCR assay using the primer pair PDS FW and PDS R (Additional file 1: Table S1). a, 1-4, Detection of mutations in plants derived from tuber transformation with A. tumefiaciens LBA4404 (PROGED::.gPDS); 5-9, detection of mutations in plants derived from tuber transformation with A. tumefiaciens gv2260 (PROGED::gPDS). Lane 9 shows the mutant PDS.5 m, the phenotype of which is shown in Fig. 3b. PCR was carried out with 36 cycles and fragments were separated on a $1 \%$ agarose gel. b, 1-5, Detection of mutations in plants derived from leaf transformation with A. tumefiaciens LBA4404 (PROGED::gPDS); 5-10, detection of mutations in plants derived from leaf transformation with A. tumefiaciens gv2260 (PROGED::gPDS). Lane 1 shows the mutant PDS.28 g, the phenotype of which is shown in Fig. 3c. PCR was carried out with 34 cycles and fragments were separated on a 1.2\% agarose gel. M, DNA ladder; D, nontransformed 'Désirée'; PDS, PCR fragments amplified from intact genomic DNA; MlyI-PDS, PCR fragments amplified from Mlyl-digested genomic DNA

fluorouracil (5-FU) [17]. Earlier, we found that in the presence of recombinase, 3 weeks of positive selection followed by negative selection was optimal for the isolation of marker-free transgenic lines [15]. Since we removed the recombinase from the vector, a shorter, 2-week positive selection followed by negative selection was undertaken for PDS mutagenesis using the PROGED vector. Leaves and tubers were transformed in parallel with the Agrobacterium strains gv2260 and LBA4404. In total, 44 regenerated plants were obtained; however, based on the PCR test described above, none of them carried mutations in the targeted region (Additional file 1: Table S2).

\section{Testing the efficiency of PROGED-mediated gene editing with 3-day selection}

The negative results of 2-week selection experiments indicated that the transgenes are in an integrated stage by this period of time. Therefore, a considerably shorter, 3-day $\mathrm{Km}$ selection was applied followed by lack of selection or with counter-selection of emerging calluses and regenerating shoots carrying integrated transgenes derived from PROGED::gPDS. In parallel, a transformation experiment without any selection for the transformation event was carried out as a control. Due to the short time or even lack of selection, hundreds of regenerated shoots appeared both from tuber and leaf transformation either by Agrobacterium gv2260 or LBA4404. We hypothesised that the majority of the regenerated plants are non-transformed. Therefore, genomic DNA was isolated from groups of plants to search for PDS mutants. Each group consisted of six plants. Seven groups were tested from each transformation with 3-day $\mathrm{Km}$ selection. Nineteen positive groups were identified. Individual testing of plants by PCR resulted in the identification of 22 PDS mutants appearing with a frequency of $2-10 \%$ with no substantial difference between counter-selected and non-counter-selected plant populations (Table 2). In contrast with the majority of the plants with integrated transgenes, none of the mutant plants had a deletion large enough to be visible on a gel in the PCR test. Two chimaeric plants with a green-white

Table 1 Efficiency of PDS mutagenesis with Km selection

\begin{tabular}{lllllll}
\hline Transformed organ & Strain & Vector & No. of regenerated plants & No. of tested plants & No. of mutants & Efficiency $^{\mathbf{b}}$ (\%) \\
\hline Tuber & gv2260 & CP025 & 36 & 16 & 11 & 69 \\
& & PROGED & 24 & 8 & 7 & 88 \\
& LBA4404 & CP025 & 56 & 21 & 18 & 86 \\
Leaf & & PROGED & 28 & 17 & 8 & 47 \\
& gv2260 & PROGED & 24 & 14 & 9 & 64 \\
\end{tabular}

a Plants for testing the presence of mutation in the PDS gene were selected randomly

${ }^{\mathrm{b}}$ Efficiency (\%) of PDS mutagenesis was calculated as number of mutants detected by the restriction enzyme site loss method in PCR amplification of genomic DNA after digestion with Mlyl / number of tested plants $\times 100$ 

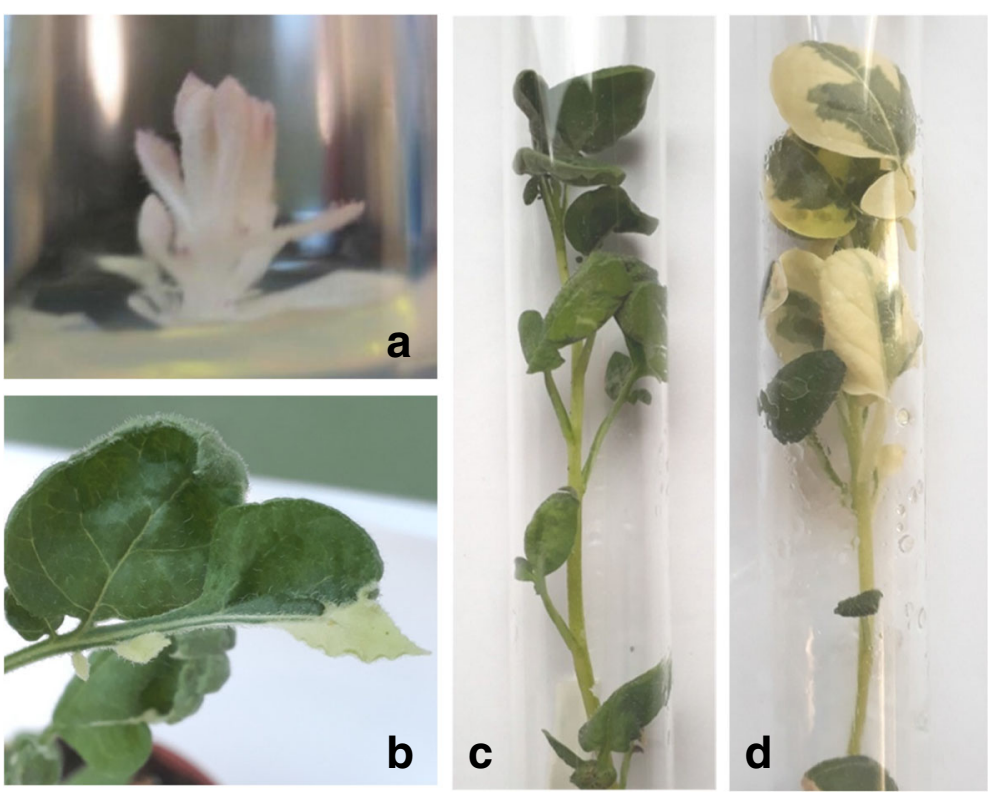

Fig. 3 Phenotypes of PDS mutants. (a) PDS.3w - albino, (b) PDS.5 m -"tabby", (c) PDS.28 g - green, indistinguishable from the wild-type, (d) PDS.10 m - "patchy" plant

mosaic phenotype were obtained. One of them was indistinguishable from the "tabby" transgenic plant shown in Fig. 3b. The other one was "patchy" and possessed larger white areas than "tabby" (Fig. 3d). From the experiment with a lack of selection, 32 groups were tested. None of the groups harboured a PDS mutant. Thus, it was concluded that the chance to find a gene-edited mutant based on the restriction enzyme site loss method in a regenerated potato plant population without any selection is less than $0.5 \%$.

Ten lines isolated after 3 days of selection, including the two chimaeras, were further investigated by PCR. Using primer pairs specific for the Cas9-scfRNA fragment, Cas9 and nptII, it was concluded that the PDS mutations in these plants were generated from transient expression of Cas 9 and $g P D S$, as no PCR fragments derived from the above listed parts of PROGED::gPDS were detected on agarose gels (five lines are shown in Additional file 3: Fig. 2).

\section{Genotyping of PDS mutants at the DNA sequence level}

The same region surrounding $g P D S$, which was sequenced from the non-transformed 'Désirée', was PCRamplified, cloned into pGEM-T Easy and Sangersequenced from 15 PDS mutants originating from different experiments (Table 3). Commercial potato cultivars are tetraploids. The 10 sequenced 'Désirée' clones represented three characteristically different types of PDS genes, which may correspond to three different alleles of PDS. Arbitrarily choosing one of them as "wild-type", a 2-bp AC deletion and a 16-bp insertion, respectively, were detected in the other two types (Additional file 2:

Table 2 Efficiency of PROGED::gPDS mutagenesis with Km selection for 3 days

\begin{tabular}{|c|c|c|c|c|c|}
\hline Transformed organ & Counter-selection & Strain & No. of groups with mutants ${ }^{\mathbf{a}}$ & Number of mutants & Efficiency $(\%)^{\mathbf{b}}$ \\
\hline \multirow[t]{4}{*}{ Tuber } & & gv2260 & 1 & 1 & 2 \\
\hline & & LBA4404 & 2 & 3 & 7 \\
\hline & $5-\mathrm{FC}$ & gv2260 & 3 & 3 & 9 \\
\hline & & LBA4404 & 2 & 2 & 5 \\
\hline \multirow[t]{4}{*}{ Leaf } & & gv2260 & 2 & 3 & 9 \\
\hline & & LBA4404 & 3 & 4 & 10 \\
\hline & $5-\mathrm{FC}$ & gv2260 & 2 & 2 & 5 \\
\hline & & LBA4404 & 4 & 4 & 10 \\
\hline
\end{tabular}

\footnotetext{
a Seven groups of regenerated plants were tested from each transformation experiment. Each group consisted of six plants

${ }^{\mathrm{b}}$ Efficiency (\%) of PDS mutagenesis was calculated as number of mutants detected by the restriction enzyme site loss method in PCR amplification of genomic DNA after digestion with Mlyl / number of tested plants (7 groups $\times 6$ plants $=42) \times 100$
} 
Table 3 Phenotype and the detected mutations in the PDS-mutated potato plants

\begin{tabular}{|c|c|c|c|c|c|c|c|c|}
\hline \multirow{2}{*}{$\begin{array}{l}\text { Tf. } \\
\text { organ }\end{array}$} & \multirow[t]{2}{*}{ Selection } & \multirow[t]{2}{*}{ Strain } & \multirow[t]{2}{*}{ Mutant } & \multirow{2}{*}{$\begin{array}{l}\text { Pheno } \\
\text { type }\end{array}$} & \multicolumn{4}{|l|}{ Genotype $^{*}$} \\
\hline & & & & & Allele 1 & $\begin{array}{l}\text { Allele } 2 \\
\text { (-AC) }\end{array}$ & $\begin{array}{l}\text { Allele } 3 \\
\text { (+ } 16 \text { bp) }\end{array}$ & $\begin{array}{l}\text { Allele } 4 \\
\text { (variant) } \\
\end{array}$ \\
\hline \multirow[t]{6}{*}{ Tuber } & $\mathrm{Km}$ & gv2260 & PDS.12 g & green & $\Delta 165$ (2) $\Delta 5(2)$ & & $\Delta 165(1)$ & \\
\hline & & & PDS.5 m & $\begin{array}{l}\text { mosaic } \\
\text { (tabby) }\end{array}$ & $\begin{array}{l}\Delta 1(1) \\
\text { Wt (2) }\end{array}$ & & wt (1) & $\Delta 165(7)$ \\
\hline & & & PDS.3w & white & & & & $\begin{array}{l}\Delta 146(1) \\
\Delta 166(2)\end{array}$ \\
\hline & & & PDS.11W & white & $\Delta 104(2)$ & & & \\
\hline & & LBA4404 & PDS.28 g & green & $\begin{array}{l}\Delta 35+T / A(5) \\
\text { wt (1) }\end{array}$ & & & \\
\hline & & & PDS.34 g & green & & wt (1) & & $\Delta 165$ \\
\hline \multirow[t]{5}{*}{ Tuber } & $3 d-K m$ & gv2260 & PDS.73 g & green & wt (3) & wt (2) & $\Delta 1(1)$ & \\
\hline & $\begin{array}{l}3 \mathrm{~d}-\mathrm{Km} \\
15-\mathrm{FC}\end{array}$ & & PDS.65 g & green & $\begin{array}{l}\Delta 1(1) \\
\text { wt (3) }\end{array}$ & wt (1) & & \\
\hline & $3 d-K m$ & LBA4404 & PDS.48 g & green & $\begin{array}{l}\Delta 2+T / A(1) \\
\text { wt (1) }\end{array}$ & wt (2) & & \\
\hline & & & PDS.9 m & $\begin{array}{l}\text { mosaic } \\
\text { (tabby) }\end{array}$ & $\Delta 3(1)$ & $\Delta 1(3)$ & wt (3) & \\
\hline & $3 \mathrm{~d}-\mathrm{Km} / 5-\mathrm{FC}$ & & PDS.10 m & $\begin{array}{l}\text { mosaic } \\
\text { (patchy) }\end{array}$ & wt (3) & & & $\Delta 117(1)$ \\
\hline \multirow[t]{4}{*}{ Leaf } & $3 d-K m$ & gv2260 & PDS.10 g & green & $\begin{array}{l}\Delta 1+\Delta 3(1) \\
\text { wt (2) }\end{array}$ & wt (1) & & \\
\hline & $3 d-K m$ & LBA4404 & PDS.1 g & green & $\begin{array}{l}\Delta 2(1) \\
\text { wt (6) }\end{array}$ & & & \\
\hline & & & PDS.33 g & green & $\begin{array}{l}\Delta 2+G / A(1) \\
\text { wt (8) }\end{array}$ & & & \\
\hline & $3 \mathrm{~d}-\mathrm{Km} / 5-\mathrm{FC}$ & & PDS.5 g & green & wt (3) & $\begin{array}{l}\Delta 2+T / C(1) \\
w t(1)\end{array}$ & & \\
\hline
\end{tabular}

${ }^{*} \Delta$ numbers indicate the size of the deletions in bp. Numbers in parenthesis specify the number of clones with identical sequence. /, base pair changes; wt, wild-type

Fig. S1). DNA sequence analysis of the clones derived from PDS mutants identified the fourth allele with a sequence alteration at a few bp upstream of the $g P D S$ sequence (Additional file 2: Fig. S3,4,7,12).

The DNA sequence analysis supported the result of the PCR test because large deletions extending from 35 to $166 \mathrm{bp}$ were detected in mutants obtained by continuous $\mathrm{Km}$ selection (Table 3 and Additional file 2: Fig. 27), while with temporary $\mathrm{Km}$ selection, deletions of only a few bp and 1-bp substitutions in three mutants were obtained (Table 3 and Additional file 2: Fig. 8-16). The mutations were extended to all four alleles; however, biallelic mutations were found only in three mutants (Table 3 and Additional file 2: Fig. S2,3,11). Wild-type and mutant sequences or two different mutations in the same allele were detected in eight out of ten green plants (Table 3 and Additional file 2: Fig. S2,6,9,10,13,14,15,16) indicating that not only "tabby" and "patchy", but several green plants were also chimaeras. Due to the limited number of sequenced clones (Table 3), the presence of additional mutations, especially in the albino and chimaeric plants with white areas, is highly probable.

\section{Discussion}

Producing transgene-free targeted mutants from vegetatively propagated, highly heterozygous and selfincompatible commercial potato cultivars is a challenging task. In this study, we tested the possibility of using positive/negative selection for mutant enrichment in a regenerating plant population obtained after Agrobacteriummediated gene editing via Cas9 and sgRNA. The PDS gene was targeted because of the easily recognisable albino phenotype of null mutants. Since $100 \%$ identity between the DNA sequences of the 20-bp oligo used successfully for gene editing in tomato [16] and the corresponding region of the potato cultivar 'Désirée' was detected, we used this oligo for mutagenesis in the potato cultivar 'Désirée'. Since the oligo carried a MlyI recognition site, the restriction enzyme site loss method was used to easily detect mutations in the targeted region by PCR. Nevertheless, it has been shown that Cas 9 preferentially cleaves the targeted region and generates blunt-ended double-strand break (DSB) $3 \mathrm{bp}$ upstream of PAM motif [18]. Thus, in our experiments, mutants with small indels not extending to the MlyI site located 14 bp upstream of PAM motif (Fig. 1) were lost. 
A novel vector suitable for gene editing with positive/ negative selection was constructed. It was demonstrated that using only the positive selection function of the new vector PROGED carrying only the right border $(R B)$ sequence, the new vector is as efficient in gene-editing as the traditional vector pCAMBIA with $R B$ and left border $(L B)$ sequences. With continuous selection on $\mathrm{Km}$, the frequency of mutations detected by the restriction enzyme site loss method varied between 47 and $88 \%$. Similarly, high efficiencies were detected with Agrobacterium-mediated gene editing with stable transgene integration for the $A L S$ gene in potato $[6,7,14]$ or for $P D S$ in other plant species: tomato, poplar, apple, rice, watermelon, cassava, grape, banana, coffee, pear, chicory, strawberry and cabbage [16, 19-30].

Using 2-week positive selection continued with negative selection, no transgene-free mutant plants could be isolated. The use of 3-day positive selection continued with negative selection generated PDS mutants with a frequency of $5-10 \%$. This frequency, however, did not differ significantly from the efficiency of 3-day positive selection without subsequent negative selection, which varied from 2 to $10 \%$, while without positive selection no mutants detectable by the restriction enzyme site loss method appeared. Using tobacco as a model plant and an intron-containing GUS gene as a marker, Chen et al. [13] also observed that transient expression of T-DNA genes in inoculated leaf discs peaked 3-4days after Agrobacterium infection in the absence of $\mathrm{Km}$ selection. While in the case of tobacco, high-throughput mutant screening protocol had to be used for the identification of mutants [13], our results indicated that the Agrobacterium-mediated transformation and gene-editing by the CRISPR/Cas9 system is sufficiently efficient in potato that mutants can be obtained using a simple PCR screen of plants regenerated after 3 days of positive selection. This type of selection can be performed with any traditional binary vectors.

Stable integration of Cas9 and $g P D S$ generated large deletions extending up to $166 \mathrm{bp}$ in the PDS gene. Such large deletions are rarely detected in other plant species. However, this phenomenon is not without examples, as large deletions were identified in the Gn1a gene of rice and the ALARP gene of cotton [31,32]. Deletions larger than $100 \mathrm{bp}$ are generally found only after mutagenesis with double or multiple sgRNA constructs [30, 33-38]. In potato, a deletion larger than $100 \mathrm{bp}$ was detected in one out of nine mutants obtained in the Pi transportrelated $\mathrm{PHO} 1$ gene [39]. Makhotenko et al. [40] reported two potato mutants with deletions larger than $60 \mathrm{bp}$ in the COILIN gene implicated in virus resistance, which were generated from apical meristem cells either by bioballistics with gold microparticles or infiltration with chitosan microparticles decorated with the Cas9/sgRNA
RNP complex. Earlier publications with single sgRNA and transgene integration reported a maximum of $18 \mathrm{bp}$ in the $I A A$ gene and $17 \mathrm{bp}$ in the $A L S$ gene of potatoes $[4,6]$.

In contrast with stable integration, transient expression of Cas 9 and $g P D S$ resulted in small deletions and with 1-bp substitutions in certain lines. The only exception was the line with large white patches harbouring a 117-bp deletion. Since the same construct was used for both types of experiments, we suppose that the difference is based on the different amounts of Cas9 and sgRNA produced in cells. While in the case of stable integration, both elements are produced continuously in large amounts upon regeneration, the transient expression provides only low amounts of components for a short period of time and opens the door to the DNA repair mechanism.

The targeted mutagenesis of the PDS gene in different plant species highlighted the general problem of chimaerism of Agrobacterium-mediated transgenesis. Greenwhite mosaic plants were isolated after PDS mutagenesis in tomato, rice, watermelon, cassava, grape, banana, apple, pear, strawberry and cabbage $[16,20-25,27,29,30]$. Mutation types and inheritance patterns in later generations were studied in tomato and rice $[16,21]$. Out of tomato $\mathrm{T}_{0}$ plants, $64 \%$ had chimaeric mutations, in which at least two mutation types occurred in each, including deletions, insertions and combined mutations. In chimaeras, new mutation types were observed due to the existence of wild-type copies. Segregation patterns of the chimaeras were not predictable, and a number of new mutants were found in the $\mathrm{T}_{1}$ lines [16]. Unpredicted segregations, with more mutants than theoretically expected, were also frequently found in rice $T_{1}$ plants, indicating that inherited Cas 9 s were still active in later generations and could induce new mutations in the progeny [21]. Although Cas 9 was also present in our PDS mutants obtained by continuous Km selection, the white areas did not grow on "tabby" plants, and no white areas appeared on green plants even after a year of vegetative propagation. Low amounts of Cas 9 mRNA could be detected in these lines by RT-PCR. Nevertheless, as we do not know the level of mosaicism, we cannot reach conclusions regarding the level of Cas 9 expression in those cells that harbour Cas 9 . The frequency of chimaeric mutations also cannot be calculated from our experiments because plants carrying mono-, bi-, or triallelic mutations in the PDS gene may be as green as wildtype plants and can be either chimaeric or non-chimaeric. Faize et al. [41] found that chimaeras are a highly frequent phenomenon observed after regenerating tobacco and apricot transgenic plants and suggested using real-time PCR quantification of the transgene in comparison to a housekeeping gene during sub-cultivation periods or in different organs if antibiotic selection is used. Chimaeras 
can be dissociated by iterative regeneration. This method is, however, a time-consuming approach with unpredictable outcomes. Crossing out the mutations from our PDS mutant plants would be necessary to get information on the frequency of chimaeras in $P D S$-edited population of potato generated by Agrobacterium-mediated transformation.

\section{Conclusions}

This work shows that Agrobacterium-mediated gene editing in potatoes is an efficient method either by tuber or leaf transformation and using either A. tumefaciens strain gv2260 or LBA4404. Large deletions can be generated by continuous positive selection for stable transgene integration, while small deletions and nucleotide substitutions are derived from the transient expression of the Cas9 system. Stable integration of Cas9 and sgRNA can generate mutations in all four copies of a gene in the tetraploid genome of potato, as demonstrated by the appearance of albino plants in the PDS mutant population. Nevertheless, irrespective of the selection method, chimaeras appear in the mutant population. Despite the presence of Cas 9 and $s g R N A$ in the genome, the $\mathrm{T}_{0}$ plants propagated from stem segments had a stable phenotype, suggesting that the expression of $\operatorname{Cas} 9$ and $s g R N A$ is silenced or that the DNA repair system is highly active during the vegetative growth phase in potato. Gene function studies in potatoes have always been performed on the $T_{0}$ generation of transgenic plants. Since the phenotype of the gene-edited transgenic lines propagated in vitro is stable, these plants are suitable for gene-function studies.

\section{Methods}

\section{Vector constructions}

The 20-bp oligo defined by [16] with AarI sites was synthesised by Integrated DNA Technologies (IDT, Coralville, IA, USA) and inserted between the two AarI sites of CP025 [4] as annealed oligonucleotides. The highfidelity Phusion DNA polymerase (Thermo Fisher Scientific, Waltham, MA, USA) was used to amplify the Cas9gPDS construct with the primers AscI35SFW and PacIScfRNAR (Additional file 1: Table S1) following the manufacturer's instructions. The generated PCR fragment was digested with $A s c \mathrm{I}$ and $P a c \mathrm{I}$ and inserted between the corresponding sites of PROGMO [15], thereby replacing the recombinase in the vector and resulting in PROGED::gPDS (Fig. 1).

\section{Plant growth conditions and transformation}

Virus-free and sterile shoots of the commercial potato (Solanum tuberosum L.) cultivar 'Désirée' were obtained from Fritz Lange KG (Bad Schwartau, Germany), cultivated under axenic conditions for tissue culture at the Max Planck Institute of Molecular Plant Physiology
(Golm, Germany) [42] and transferred to our laboratory, where the plants were propagated in vitro from stem segments in MS medium (w/v) [43] without vitamins containing $2 \%(\mathrm{w} / \mathrm{v})$ sucrose and solidified with $0.8 \%$ agar (rooting medium; RM) in tubes closed with paper plugs. For tuber transformation, the tops of the plants were transferred into 500-ml Erlenmeyer flasks (2 plants/flask) containing $160 \mathrm{ml} \mathrm{RM}$ and incubated in culture room at $24^{\circ} \mathrm{C}$ under a light regime of $16 \mathrm{~h}$ light at $75 \mu \mathrm{mol} \mathrm{m}{ }^{-2} \mathrm{~s}^{-1}$ intensity and $8 \mathrm{~h}$ of darkness. Tubers appeared on plants 4 months after planting. Tubers with a diameter of approximately $1 \mathrm{~cm}$ were cut to fine slices. The slices were co-cultured with the Agrobacterium tumefaciens strains gv2260 [44] or LBA4404 [45] carrying a recombinant plasmid for 2 days in the dark at $24{ }^{\circ} \mathrm{C}$. Shoots were regenerated from tuber slices as described by [46] in 500-ml Erlenmeyer flasks closed with paper plugs in the presence of $500 \mathrm{mgl}^{-1}$ cefotaxime (Cf) to eliminate the Agrobacterium from the culture. The medium was supplemented with $50 \mathrm{mg} \mathrm{l}^{-1} \mathrm{Km}$ and/ or $150 \mathrm{mg} \mathrm{l}^{-1} 5$-FC, depending on the experimental design. Regenerated shoots were excised and placed either into paper-plugged tubes or Phytatrays (Sigma, St. Louis, MI, USA) containing RM medium for rooting. The RM medium was supplemented with $\mathrm{Cf}$ or $\mathrm{Cf}+\mathrm{Km}$ when regenerated shoots were derived from continuous $\mathrm{Km}$ selection.

For leaf transformation, the potato cultivar 'Désirée' was propagated in vitro in $500-\mathrm{ml}$ jars in MS medium containing $2 \%(\mathrm{w} / \mathrm{v})$ sucrose and solidified with $0.8 \%$ agar (5 plants/jars). Transformation and regeneration of shoots from leaves of 1-month-old plants was carried out according to [42]. The Agrobacterium strains, Km and 5-FC concentrations used were the same as for tuber transformation, but the concentration of $\mathrm{Cf}$ was decreased to $250 \mathrm{mgl}^{-1}$.

\section{Molecular biology techniques}

For basic techniques, e.g., plasmid DNA isolation, digestion with restriction enzymes, transformation of Escherichia coli, agarose gel electrophoreses, PCR, etc. instructions of [47] were followed. Genomic DNA from potato was isolated according to [48], while RNA from leaves of in vitro-grown plants was purified by the method of [49]. The Maxima H Minus First Strand cDNA Synthsis Kit with ds DNAse (Thermo Fisher Scientific, Walthman, MA, USA) was used to convert mRNA to cDNA.

The primer pair PDS Fw and PDS R (Additional file 1: Table 1) were used for detection of mutations in PDS gene by PCR. Two hundred ng of potato genomic DNA was used as a template without digestion and after digestion with MlyI. The MlyI-digested DNA was precipitated by ethanol and sodium acetate, washed with $70 \%$ ethanol, 
dried and dissolved in distilled water [47] before using it for PCR.

Sanger-sequencing was performed at the company BIOMI (Gödöllö, Hungary) and analysed by NCBI blast (https://blast.ncbi.nlm.nih.gov/Blast.cgi) and the multiple alignment tool Clustal Omega (www.ebi.ac.uk/Tools/ msa/clustalo).

\section{Supplementary information}

Supplementary information accompanies this paper at https://doi.org/10. 1186/s12896-020-00621-2

Additional file $\mathbf{1}$ Table S1. Primer sequences; Table S2. Efficiency of PDS mutagenesis with $\mathrm{Km}$ selection for 2 weeks followed by counterselection with $5-\mathrm{FC}$.

Additional file 2 Figure S1. Multiple sequence alignment of PDS fragments cloned from the potato cultivar 'Désirée'. Figure S2. PDS.12g. Figure S3. PDS. $5 \mathrm{~m}$. Figure S4. PDS.3w. Figure S5. PDS.11w. Figure S6. PDS.28g. Figure S7. PDS.34g. Figure S8. PDS.73g. Figure S9. PDS.65g. Figure S10. PDS.48g. Figure S11. PDS.9m. Figure S12. PDS.10m. Figure S13. PDS.10g. Figure S14. PDS.1g. Figure S15. PDS.33g. Figure S16. PDS.5g.

Additional file 3: Figure S1. Detection and expression of Cas9 in PDS mutants obtained after continuous Km selection. Figure S2. Detection of the lack of transgenes in PDS mutants obtained after 3 days of $\mathrm{Km}$ selection.

\section{Abbreviations}

ALS: Acetolactate synthase; Cf: Cefotaxime; 5-FC: 5-fluorocytosine; IAA: Indole acetic acid; Km: Kanamycin; PDS: Phytoene desaturase

\section{Acknowledgements}

We are grateful to M. Kiss, technician for plant propagation and transformation. We thank S. Wang (Henan Agricultural University, Zhengzhou, China) for CP025.

\section{Authors' contributions}

ZB designed and performed the majority of the experiments with the technical help of M. Kiss, whose contribution is acknowledged, and wrote the manuscript; EC and W participated in the selection and characterisation of PDS mutants; and MK constructed the PROGED::gPDS vector. All authors read and approved the final manuscript.

\section{Funding}

This work was financially supported by the Hungarian grant office NKFI (grant number: K-120641). All other aspects of the project as design of the study, experimental work, interpretation of data and writing of the manuscript was executed by the authors.

\section{Availability of data and materials}

All data generated or analysed during this study are included in this published article and its supplementary information files.

\section{Ethics approval and consent to participate}

Not applicable.

\section{Consent for publication}

Not applicable.

\section{Competing interests}

ZB is a plant biotechnology associate editor for BMC Biotechnology. She has played no editorial role in this paper.
Received: 2 September 2019 Accepted: 4 May 2020

Published online: 12 May 2020

\section{References}

1. Jang $G$, Joung $Y H$. CRISPR/Cas-mediated genome editing for crop improvement: current applications and future prospects. Plant Biotechnol Rep. 2019;13:1-10.

2. Van Eck J. Genome editing and plant transformation of solanaceous food crops. Curr Opin Biotechnol. 2018:49:35-41.

3. Yamamoto T, Kashojiya S, Kamimura S, Kameyama T, Ariizumi T, Ezura H, Miura K. Application and development of genome editing technologies to the Solanaceae plants. Plant Physiol Biochem. 2018;131:37-46.

4. Wang S, Zhang S, Wang W, Xiong X, Meng F, Cui X. Efficient targeted mutagenesis in potato by the CRISPR/Cas9 system. Plant Cell Rep. 2015;34:1473-6.

5. Shan Q, Wang Y, Li J, Zhang Y, Chen K, Liang Z, Zhang K, Liu J, Xi JJ, Qiu JL, Gao C. Targeted genome modification of crop plants using a CRISPR-Cas system. Nat Biotechnol. 2013;31:686-8.

6. Butler NM, Atkins PA, Voytas DF, Douches DS. Generation and inheritance of targeted mutations in potato (Solanum tuberosum L.) using the CRISPR/Cas system. PLoS One. 2015:10:e0144591.

7. Butler NM, Baltes NJ, Voytas DF, Douches DS. Geminivirus-mediated genome editing in potato (Solanum tuberosum L.) using sequence-specific nucleases. Front Plant Sci. 2016;7:1045.

8. Slater AT, Cogan NO, Hayes BJ, Schultz L, Dale MF, Bryan GJ, Forster JW. Improving breeding efficiency in potato using molecular and quantitative genetics. Theor Appl Genet. 2014;127:2279-92.

9. Andersson M, Turesson H, Nicolia A, Fält AS, Samuelsson M, Hofvander P. Efficient targeted multiallelic mutagenesis in tetraploid potato (Solanum tuberosum) by transient CRISPR-Cas9 expression in protoplasts. Plant Cell Rep. 2017;36:117-28.

10. Andersson M, Turesson H, Olsson N, Fält AS, Olsson P, Gonzalez MN Samuelsson M, Hofvander P. Genome editing in potato via CRISPR-Cas9 ribonucleoprotein delivery. Physiol Plant. 2018;164:378-84.

11. Fossi M, Amundson K, Kuppu S, Britt A, Comai L. Regeneration of Solanum tuberosum plants from protoplasts induces widespread genome instability. Plant Physiol. 2019;180:78-86.

12. Sardesai N, Subramanyam S. Agrobacterium: a genome-editing tool-delivery system. Curr Top Microbiol Immunol. 2018;418:463-88.

13. Chen L, Li W, Katin-Grazzini L, Ding J, Gu X, Li Y, Gu T, Wang R, Lin X, Deng Z, McAvoy RJ, Gmitter FG Jr, Deng Z, Zhao Y, Li Y. A method for the production and expedient screening of CRISPR/Cas9-mediated nontransgenic mutant plants. Hortic Res. 2018;5:13.

14. Veillet F, Perrot L, Chauvin L, Kermarrec MP, Guyon-Debast A, Chauvin JE, Nogué $\mathrm{F}$, Mazier M. Transgene-free genome editing in tomato and potato plants using Agrobacterium-mediated delivery of a CRISPR/Cas9 cytidine base editor. Int J Mol Sci. 2019;20:E402.

15. Kondrák M, van der Meer I, Bánfalvi Z. Generation of marker- and backbonefree transgenic potatoes by site-specific recombination and a bifunctional marker gene in a non-regular one-border Agrobacterium transformation vector. Transgenic Res. 2006;15:729-37.

16. Pan C, Ye L, Qin L, Liu X, He Y, Wang J, Chen L, Lu G. CRISPR/Cas9-mediated efficient and heritable targeted mutagenesis in tomato plants in the first and later generations. Sci Rep. 2016;6:24765.

17. Gleave AP, Mitra DS, Mudge SR, Morris BA. Selectable marker-free transgenic plants without sexual crossing: transient expression of cre recombinase and use of a conditional lethal dominant gene. Plant Mol Biol. 1999;40:223-35.

18. Deltcheva E, Chylinski K, Sharma CM, Gonzales K, Chao Y, Pirzada ZA, Eckert MR, Vogel J, Charpentier E. CRISPR RNA maturation by trans-encoded small RNA and host factor RNase III. Nature. 2011:471:602-7.

19. Fan D, Liu TT, Li CF, Jiao B, Li S, Hou YS, Luo KM. Efficient CRISPR/Cas9mediated targeted mutagenesis in Populus in the first generation. Sci Rep. 2015;5:12217.

20. Nishitani C, Hirai N, Komori S, Wada M, Okada K, Osakabe K, Yamamoto T, Osakabe Y. Efficient genome editing in apple using a CRISPR/Cas9 system. Sci Rep. 2016;6:31481.

21. Ishizaki T. CRISPR/Cas9 in rice can induce new mutations in later generations, leading to chimerism and unpredicted segregation of the targeted mutation. Mol Breeding. 2016:36:165.

22. Tian S, Jiang L, Gao Q, Zhang J, Zong M, Zhang H, Ren Y, Guo S, Gong G, Liu F, Xu Y. Efficient CRISPR/Cas9-based gene knockout in watermelon. Plant Cell Rep. 2017:36:399-406. 
23. Odipio J, Alicai T, Ingelbrecht I, Nusinow DA, Bart R, Taylor NJ. Efficient CRISPR/Cas9 genome editing of Phytoene desaturase in cassava. Front Plant Sci. 2017:8:1780.

24. Nakajima I, Ban Y, Azuma A, Onoue N, Moriguchi T, Yamamoto T, Toki S, Endo M. CRISPR/Cas9-mediated targeted mutagenesis in grape. PLoS One. 2017;18:e0177966.

25. Kaur N, Alok A, Shivani C, Kaur N, Pandey P, Awasthi P, Tiwar S. CRISPR/ Cas9-mediated efficient editing in phytoene desaturase (PDS) demonstrates precise manipulation in banana cv. Rasthali genome. Funct Integr Genomics. 2018;18:89-99.

26. Breitler JC, Dechamp E, Campa C, Rodrigues LAZ, Guyot R, Marraccini P, Etienne H. CRISPR/Cas9-mediated efficient targeted mutagenesis has the potential to accelerate the domestication of Coffea canephora. Plant Cell Tiss Org. 2018;134:383-94.

27. Charrier A, Vergne E, Dousset N, Richer A, Petiteau A, Chevreau E. Efficient targeted mutagenesis in apple and first time edition of pear using the CRISPR-Cas9 system. Front Plant Sci. 2019;10:40.

28. Bernard G, Gagneul D, Dos Santos HA, Etienne A, Hilbert JL, Rambaud C. Efficient genome editing using CRISPR/Cas9 technology in chicory. Int J Mol Sci. 2019;20:1155.

29. Wilson FM, Harrison K, Armitage AD, Simkin AJ, Harrison RJ. CRISPR/Cas9mediated mutagenesis of phytoene desaturase in diploid and octoploid strawberry. Plant Methods. 2019;15:45.

30. Ma CF, Liu MC, Li QF, Si J, Ren XS, Song HY. Efficient BoPDS gene editing in cabbage by the CRISPR/Cas9 system. Hortic Plant J. 2019;5:164-9.

31. Li MR, Li XX, Zhou ZJ, Wu PZ, Fang MC, Pan XP, Lin QP, Luo WB, Wu GJ, Li $\mathrm{HQ}$. Reassessment of the four yield-related genes Gn 1a, DEP1, GS3, and IPAI in rice using a CRISPR/Cas9 system. Front Plant Sci. 2016;7:377.

32. Zhu S, Yu X, Li Y, Sun Y, Zhu Q, Sun J. Highly efficient targeted gene editing in upland cotton using the CRISPR/Cas9 system. Int J Mol Sci. 2018;19:3000.

33. Zhou H, Liu B, Weeks DP, Spalding MH, Yang B. Large chromosomal deletions and heritable small genetic changes induced by CRISPR/Cas9 in rice. Nucl Acids Res. 2014;42:10903-14.

34. Cai Y, Chen L, Sun S, Wu C, Yao W, Jiang B, Han T, Hou W. CRISPR/Cas9mediated deletion of large genomic fragments in soybean. Int J Mol Sci. 2018;19:3835.

35. Wang Z, Wang S, Li D, Zhang Q, Li L, Zhong C, Liu Y, Huang H. Optimized paired-sgRNA/Cas9 cloning and expression cassette triggers high-efficiency multiplex genome editing in kiwifruit. Plant Biotechnol J. 2018;16:1424-33.

36. Kusano $\mathrm{H}$, Ohnuma M, Mutsuro-Aoki $\mathrm{H}$, Asahi T, Ichinosawa D, Onodera H, Asano K, Noda T, Horie T, Fukumoto K, Kihira M, Teramura H, Yazaki K, Umemoto N, Muranaka T, Shimada H. Establishment of a modified CRISPR/ Cas9 system with increased mutagenesis frequency using the translational enhancer dMac3 and multiple guide RNAs in potato. Sci Rep. 2018;13:13753.

37. Enciso-Rodriguez F, Manrique-Carpintero NC, Nadakuduti SS, Buell CR, Zarka D, Douches D. Overcoming self-incompatibility in diploid potato using CRISPR-Cas9. Front Plant Sci. 2019:10:376.

38. Nawaz G, Han Y, Usman B, Liu F, Qin B, Li R. Knockout of OsPRP1, a gene encoding proline-rich protein, confers enhanced cold sensitivity in rice (Oryza sativa L.) at the seedling stage. 3 Biotech. 2019;9:254.

39. Zhou X, Zha M, Huang J, Li L, Imran M, Zhang C. StMYB44 negatively regulates phosphate transport by suppressing expression of PHOSPHATE1 in potato. J Exp Bot. 2017;68:1265-81.

40. Makhotenko AV, Khromov AV, Snigir EA, Makarova SS, Makarov W, Suprunova TP, Kalinina NO, Taliansky ME. Functional analysis of coilin in virus resistance and stress tolerance of potato Solanum tuberosum using CRISPR-Cas9 editing. Biochem Biophys Mol Biol. 2019;484:88-91.

41. Faize $M$, Faize $L$, Burgos $L$. Using quantitative real-time $P C R$ to detect chimeras in transgenic tobacco and apricot and to monitor their dissociation. BMC Biotechnol. 2010;10:53.

42. Dietze J, Blau A, Willmitzer L. Agrobacterium-mediated transformation of potato (Solanum tuberosum). In: Potrykus I, Spangenberg G, editors. Gene transfer to plants. Berlin: Springer-Verlag; 1995. p. 24-9.

43. Murashige T, Skoog F. A revised medium for rapid growth and bioassays with tobacco tissue cultures. Physiol Plant. 1962;15:473-97.

44. Deblaere R, Bytebier B, De Greve H, Deboeck F, Schell J, Van Montagu M, Leemans J. Efficient octopine Ti plasmid-derived vectors for Agrobacteriummediated gene transfer to plants. Nucl Acids Res. 1985;13:4777-88.

45. Hoekema A, Hirsch PR, Hooykaas PJJ, Schilperoort RA. A binary plant vector strategy based on separation of vir- and T-region of the Agrobacterium tumefaciens Ti-plasmid. Nature. 1983;303:179-80.
46. Stiller I, Dulai S. KondrákM, Tarnai R, Szabó L, Toldi O, Bánfalvi Z. effects of drought on water content and photosynthetic parameters in potato plants expressing the trehalose-6-phosphate synthase gene of Saccharomyces cerevisiae. Planta. 2008:227:299-308.

47. Sambrook J, Fritsch EF, Maniatis T. Molecular cloning: a laboratory manual. 2nd ed. Cold Spring Harbor: Cold Spring Harbor Laboratory Press; 1989.

48. Shure M, Wessler S, Fedoroff N. Molecular identification and isolation of the waxy locus of maize. Cell. 1983;35:225-33.

49. Stiekema WJ, Heidekamp F, Dirkse WG, van Beckum J, de Haan P, Bosch CT, Louwerse JD. Molecular cloning and analysis of four potato tuber mRNAs. Plant Mol Biol. 1988:11:255-69.

\section{Publisher's Note}

Springer Nature remains neutral with regard to jurisdictional claims in published maps and institutional affiliations.
Ready to submit your research? Choose BMC and benefit from:

- fast, convenient online submission

- thorough peer review by experienced researchers in your field

- rapid publication on acceptance

- support for research data, including large and complex data types

- gold Open Access which fosters wider collaboration and increased citations

- maximum visibility for your research: over $100 \mathrm{M}$ website views per year

At BMC, research is always in progress.

Learn more biomedcentral.com/submissions 